\section{LA ESTRUCTURA DE LAS REVOLUCIONES CIENTÍFICAS SEGÚN THOMAS KUHN EN EL ANÁLISIS DE LA HISTORIA DEL ARTE}

\author{
María Eugenia Rabadán Villalpando \\ Universidad de Guanajuato \\ marurabadan@gmail.com \\ ORCID iD: http://orcid.org/0000-0001-8121-8770
}

\section{THE STRUCTURE OF SCIENTIFIC REVOLUTIONS, ACCORDING TO THOMAS KUHN, ON THE ANALYSIS OF ART HISTORY}

Cómo citar este artículo/Citation: Rabadán Villalpando, M. E. (2017). La estructura de las revoluciones cientificas según Thomas Kuhn en el análisis de la historia del arte. Arbor, 193 (783): a372. doi: http://dx.doi.org/10.3989/ arbor.2017.783n1003

Recibido: 3 febrero 2014. Aceptado: 24 febrero 2014.
RESUMEN: Este texto plantea problemas teórico metodológicos relativos a una particular investigación sobre paisajismo moderno y contemporáneo. En él se trazan algunas cuestiones relativas a procesos dinámicos de cambios teóricos, epistemológicos y de forma en las artes visuales S. XX-XXI. El análisis, basado en el estructuralismo de las revoluciones científicas de Thomas Kuhn, tiene contenidos que responden al cuestionamiento sobre la articulación de paradigmas según Kuhn en historia de la ciencia, en vez de articulación de estilos según Heinrich Wölfflin, Meyer Schapiro o, entre otros, Ernst Gombrich en historia del arte, dado que ciencia y arte son empresas de distinta naturaleza. El acercamiento de Kuhn a la historia del arte, particularmente a la obra de Gombrich, nos llevó a trazar un paralelismo de ciencia y arte en Kuhn y al estudio de textos en los que trata la posibilidad de articulación de paradigmas en historia del arte.

PALABRAS CLAVE: Thomas Kuhn y relaciones de arte y ciencia; arte moderno y contemporáneo; cambio paradigmático y cambio visual; cambio epistemológico.
Copyright: (c) 2017 CSIC. Este es un artículo de acceso abierto distribuido bajo los términos de la licencia Creative Commons Attribution (CC BY) España 3.0.
ABSTRACT: This article offers some solutions to problems relating to the theory and methodology of a particular piece of research into modern and contemporary landscaping. It concerns the dynamic processes of theoretical, epistemological and formal changes in the visual arts in the 20th and 21st centuries. The analysis, based on the structuralism of scientific revolutions first published by Thomas Kuhn, offers some answers to the debate on the articulation of paradigms in the history of science, according to Kuhn, instead of the articulation of styles in art history, according to Heinrich Wölfflin, Meyer Shapiro and Ernst Gombrich, among others, considering science and art as entities of a different nature. Kuhn's approach to art history, particularly to the work of Gombrich, leads us to draw a parallel between science and art in Kuhn's work, where he attempted to articulate paradigms in art history.

KEYWORDS: Thomas Kuhn and the relationship between art and science; modern and contemporary art; paradigmatic change and visual change; epistemological change. 


\section{INTRODUCCIÓN}

Desde la segunda década del siglo pasado los artistas visuales han creado obras que, aun cuando su componente es el estudio visual de los fenómenos naturales y los citadinos, tanto como lo fue para Leonardo da Vinci, Alberto Durero, John Constable, William Turner o Camille Pisarro, no han sido completamente vistas como paisajes por la teoría y la historia del arte. No es el objeto de este texto aproximarse a tratar el paisajismo desde sus orígenes en el Renacimiento como lo han trabajado particular y extensamente Karel van Mander (2012), Ernst Gombrich (1950/1984, pp. 225-248), Kenneth Clark (1997), Simon Schama (1996), Malcolm Andrews (1999, pp. 25-51) entre otros autores, sino abordar ciertos aspectos clave en el despliegue del paisajismo en el contexto del profundo cambio de principios del siglo pasado en las artes visuales -un cambio que, desde nuestra perspectiva, es paradigmático más que estilístico-y cómo ha dejado a su paso diversos campos de investigación en los cuales los artistas han seguido estudiando visualmente la forma en cómo pensamos, construimos y habitamos la naturaleza y las ciudades. Para ello hemos considerado, como referente fundamental, la teoría estética del paisaje de Leonardo da Vinci que -de acuerdo con Ernst Gombrich- había escrito antes de que el primer paisaje hubiese sido pintado (Gombrich, 1950/1984, p. 231). En Botánica para pintores y otros elementos del paisaje da Vinci había propuesto estudiar visualmente cada uno de estos componentes integrantes del género independientemente de lo narrativo -el modo de ver los árboles, las ramificaciones, las hojas, el movimiento del viento, la atmósfera, la luz, la sombra, el humo, las casas...-; (González García, 2004, pp. 315-346); asimismo en El Parangón había analizado la pintura y, en una generalidad, pensado la pintura de paisaje en los siguientes términos:

Si [el pintor] quiere crear parajes y desiertos, lugares umbrosos o sombríos para la estación cálida, puede hacerlo, y también lugares calurosos para la estación fría. Si quiere valles o, desde las altas cumbres de los montes, descubrir una vasta campiña o, desde allí, divisar el horizonte del mar, es muy dueño de hacerlo; y lo es si desde los valles profundos quiere ver las altas montañas, los valles profundos y las playas. En efecto, todo lo que en el universo es, por esencia, presencia o ficción, será primero en la mente del pintor y después en sus manos. Y son aquellas cosas tan excelentes, que engendran una proporcionada armonía con sólo contemplarlas un instante, cual ocurre con la naturaleza (González García, 2004, p. 48).
Las artes visuales a lo largo de los siglos XX-XXI han seguido creando estudios visuales sobre la naturaleza y las ciudades -el mismo tema de la pintura tratado por da Vinci-, independientemente de que la forma Gestalt visual haya cambiado completamente con relación a la de las obras del Renacimiento al postimpresionismo. Estas dejaron de ser representaciones pictóricas sobre lienzo, cuando los pintores cubistas descubrieron que lo que se hace al pintar deriva del conocimiento ${ }^{1}$. Desde una perspectiva epistémica es posible ver que dicha transformación ha implicado la integración al arte occidental del conocimiento formal -abstracto y conceptual- ${ }^{2}$ lo cual fue cambiando articuladamente la obra en la comunidad artística en el lapso comprendido básicamente entre 1907 y 1915. Los estudios visuales de lo natural y las ciudades -al ser un segmento de las artes visuales- han sido consustanciales a esta mutación; entonces comienzan a oponerse a los paisajes anteriores al cubismo, principalmente los tratados de forma abstracta o conceptual. Es factible, por tanto, catalogar como paisajes los siguientes trabajos creados en pleno cambio revolucionario: el conjunto de tres acuarelas y gouaches titulados de igual forma Paisaje relacionado con Los segadores (1907) de Pablo Picasso (Daix y Rosselet, 1979, p. 201); Muelle y Océano I - Muelle y Océano IV (1914), Fachada de iglesia (1914), Composición en blanco y negro (1915) de Piet Mondrian que, respectivamente, son estudios visuales sobre el océano, la ciudad, y el firmamento visto desde Domburg que, según Mondrian, son obras abstractas equivalentes a las naturalistas sobre la ciudad y la naturaleza: "[...] la naturaleza me emociona profundamente. Solo que la pinto de otro modo." (Mondrian, 2005, p. 9; Joosten, 1998); Farmacia (1914), Handmade Stereopticon (1918-1919) de Marcel Duchamp, son ready-mades ayudados sobre paisajes y ambos son estudios visuales-estereoscópicos-del espacio; Aire de París (1919) del propio Duchamp, es un ready-made que presenta ya -no representa- un segmento del paisaje de la ciudad de las luces; Hans Belting ha descrito este fenómeno de manera comparable con la nuestra cuando analiza Placas de vidrios rotativos (1920) del mismo autor: "A diferencia del Gran Vidrio, ese trabajo no representa una máquina sino que es en sí misma una máquina, una clase de "arte máquina" (Belting, 2009, p. 60); el Cuadrado negro (1915) de Kasimir Malevich, que es un estudio visual sobre la sustracción del horizonte del plano pictórico: "Yo -afirma Malevich- he destruido el anillo del horizonte y me salí del círculo de los objetos, el anillo del horizonte que ha aprisionado al artista y a las formas de la naturaleza." (Male- 
vich, 1915, p. 118). Cada una de estas obras ha seguido siendo un estudio visual sobre la naturaleza o sobre la ciudad, pero su creación súbitamente comenzó a ser guiada por nuevas formas de conocimiento en el contexto de las artes visuales. Estos cambios teóricos modificaron la Gestalt visual de las obras, pero ello no motivó ni ha motivado la desaparición de los estudios visuales sobre el paisaje. Es evidente que los artistas entonces comienzan a pensar formas de paisajismo completamente nuevas: Umberto Boccioni publica en su manifiesto Contra el paisaje y la vieja estética: "Más aún, auguramos, y pronto, la nivelación y la destrucción del paisaje tradicional, que fue inventado por los artistas del pasado, entre otras cosas, porque desde los impresionistas hasta hoy se ha gestado uno distinto que espera su glorificación [...]" (Boccioni, 1994, p. 17). De igual manera, el año del primer ready-made, Marcel Duchamp escribe la siguiente declaración programática sobre paisajismo en la sección "Diccionarios y atlas" de En Infinitivo "Caja blanca»:

\section{Un «paisajismo» geográfico \\ «a la manera» de los mapas geográficos - pero \\ El paisajista desde lo alto de un aero - \\ Después el viaje sobre los sitios ( $400 \mathrm{~km}$ ) notas tomadas es decir por ejemplo número de casas en cada pueblo, o también número de sillas Luis XV en cada casa \\ El paisaje geográfico (con perspectiva, o sin perspec- tiva, vista desde plano como los mapas) podría regis- trar toda clase de cosas, tener una leyenda, tomar un aspecto estadístico- \\ También existe el «paisajismo geológico: Terrenos dis- tintos colores distintos - \\ ¡Qué mina!}

Paisajismo meteorológico (Barometría, termometría, etc...) (Duchamp, 1913/1978, p. 93).

Si estas obras hubiesen sido fechadas para la segunda mitad del siglo XX no parecerían tan extrañas, pero son ejemplos del cambio revolucionario de principios del siglo pasado, son los primeros trabajos contrarios al paradigma anterior y su presencia perturba cuando los asociamos con la palabra paisaje si no hemos aprendido a percibirlos como estudios visuales sobre la naturaleza y las ciudades, pero plasmados en una Gestalt visual completamente distinta en ese momento.

La parte acumulativa del fenómeno muestra que las pinturas abstractas como Paisaje California (1958), Verano otoño (1961) de Lee Mullican, que son estudios visuales sobre la luz y el paisaje, tienen relación con los paisajes modernos abstractos de referencia
(Pittman, Gerstler y Eliel, 2006); asimismo Estudio para Tenayuca, (ca. 1940), Estudio para Monte Alban (1941) de Joseph Albers son dibujos técnicos relativos al espacio en los edificios precolombinos de las ciudades; obras del arte conceptual como Los mil ríos más largos del mundo (1970-1977) de Alighiero Boetti, que parece derivado del programa duchampiano; igualmente Círculo en los Andes (1972) de Richard Long; y El campo de relámpagos (1977), Quemado, Nuevo México, de Walter De Maria, todos ellos son estudios visuales sobre la naturaleza: "Me gustan los desastres naturales -afirma De Maria-y pienso que pueden ser la más alta forma de arte posible para experimentar" (Kastner, 2012, p. 24); Y ustedes fueron victoriosos después de todo (1988) de Hans Haacke, la intervención a la Mariensäule [Columna a la Virgen María] en Graz, Austria, que conmemora la anexión de Austria a Alemania en 1938 (Grasskamp, Nesbit y Bird, 2004, p. 73): es un estudio visual sobre la ciudad, la historia, la política y la institución del arte, y es paradigmática de Fuente (1917) de Duchamp -independientemente de que este trabajo duchampiano no sea un paisaje(Bordieu, 1995, p. 96). Hans Belting ha pensado este fenómeno, de manera comparable con nuestro análisis, cuando ha afirmado que las pinturas futuristas todavía le parecen modernas e incluso más que muchas de las obras del arte contemporáneo (Belting, 2010). Lo mismo había sucedido a John Berger, a quien en la década de los años sesenta sorprendía ver que las obras cubistas más extremas hubiesen sido pintadas cincuenta años antes y, al mismo tiempo, le dejaban la impresión de que aún fuesen a ser pintadas (Berger, 1969/2002, p. 71). Por otra parte, si fuese posible realizar un pliegue temporal, y súbitamente hacer que Leonardo da Vinci, Joaquim Patinir, Vincent van Gogh o Paul Cézanne presenciasen las obras de referencia del periodo revolucionario o las de la segunda mitad del siglo pasado como 7000 Robles (1982-1986) de Joseph Beuÿs, Roden Crater (1977-2016) de James Turrell o Línea hecha caminando (1967) de Richard Long, de pronto, dichos pintores difícilmente habrían tenido elementos teóricos para ver estas obras como arte -o como paisajes-: para ello tendrían que alterar la manera de pensar y ver las formas de arte $-y$ de paisaje- posteriores al cambio revolucionario, lo cual nos lleva a examinar precisamente el momento a partir del cual se ha dejado de agregar conocimiento a lo ya conocido sobre arte, y se ha comenzado a gestar una nueva forma contraria e incompatible-competidora diría Kuhn-: lo cual significa que ha comenzado a articularse un nuevo paradigma en las artes visuales occidentales. Este es el principal problema por el 
cual nos hemos aproximado al estudio de las reestructuraciones de la percepción y los cambios de forma Gestalt visual tratados por Thomas Kuhn en El estructuralismo de las revoluciones científicas (Kuhn, 1995, pp. 92-111). Ciencia y arte, de acuerdo con Kuhn, son empresas de distinta naturaleza (Kuhn, 1969, pp. 403407), pero ello no obsta para fundamentar la articulación de paradigmas en arte, y ver -en sus acepciones cognitiva y visual- lo que las teorías de estilo no han contemplado en el paisajismo: la evidencia de episodios de carácter no acumulativo así como de carácter acumulativo que, por contraste, agregan conocimiento altamente especializado a lo conocido como arte. Estudiamos la aproximación de Kuhn a la historia del arte, lo cual es el principal objetivo de este texto, dado que a través de su modelo es factible conceptuar y ver paisajismo en obras que no habíamos percibido de esta forma previamente.

\section{COMENTARIOS SOBRE CIENCIA Y ARTE}

La obra de Thomas Kuhn ha sido asociada con el estudio del fenómeno artístico desde que fuera publicada por primera vez La estructura de las revoluciones científicas, en 1962. En su libro, al analizar el problema del progreso a través de las revoluciones este historiador de la ciencia se pregunta por qué debe progresar continuamente la ciencia cuando, por ejemplo, el arte, la teoría política y la filosofía no lo hacen (Kuhn, 1995, p. 247). Para dar respuesta a estas preguntas, basándose en los trabajos del historiador del Instituto Warburg Ernst Gombrich, Kuhn se refiere a la concepción del progreso artístico en la antigüedad y el Renacimiento, y al diferente tipo de pensamiento, no progresivo, que en la actualidad se tiene sobre esta cuestión:

Durante muchos siglos, tanto en la antigüedad como en los comienzos de la Europa moderna la pintura fue considerada la disciplina acumulativa. Durante esos años, se suponía que la meta del artista era la representación. Los críticos y los historiadores, como Plinio y Vasari, registraron con veneración la serie de inventos que, desde el escorzo hasta el claroscuro, habían hecho posible, sucesivamente, representaciones más perfectas de la naturaleza, pero esos son también los años, particularmente durante el Renacimiento, cuando no se consideraba que hubiera una gran separación entre las ciencias y las artes. Leonardo era sólo uno entre muchos hombres que pasaba libremente de uno a otro campo, los que sólo más tarde se hicieron categóricamente distintos. [...] Sólo cuando éstas últimas [la pintura y la escultura] renunciaron de manera inequívoca a la representación como finalidad y comenzaron a aprender nuevamente de modelos antiguos, obtuvo su profundidad actual la separación que, hoy día, damos por sentada (Kuhn, 1995, pp. 248-249).

Kuhn, a pie de página, hace mención de Arte e ilusión. Estudio sobre la psicología de la representación pictórica (1960/1982) de Ernst Gombrich; aunque también debió haber estudiado "La concepción renacentista del progreso artístico y sus consecuencias" una conferencia dictada en 1952, como veremos más abajo. Arte e llusión es un estudio sobre la psicología de la percepción en el contexto de la historia del arte desde la antigüedad. Principalmente trata de señalar la complejidad de los procesos de percepción que implica la formación y lectura de las imágenes. Es un estudio que Gombrich emprendió con el objeto de fundamentar el análisis de las imágenes y el enigma implícito en la articulación de los estilos; al mismo tiempo examina cómo la historia de la representación se encuentra confundida con la psicología de la percepción.

Kuhn debió de haberse interesado muy especialmente en la exposición crítica de la historiografía del principal problema estudiado por Gombrich para dar respuesta a la cuestión del progreso científico planteada arriba, dado que el argumento del historiador británico es comparable con lo dicho por Kuhn:

[...] Y en verdad puede decirse que el progreso del arte encaminado a tal meta fue para el mundo antiguo lo que el progreso de la técnica es para el moderno: el modelo del progreso en sí. Plinio contaba la historia de la escultura y de la pintura como historia de inventos, asignando a artistas individuales logros definidos en la copia de la naturaleza [...] En el Renacimiento, fue Vasari quien aplicó la misma técnica a la historia de las artes en Italia, desde el siglo XIII al XVI. Vasari nunca deja de pagar tributo a los artistas del pasado que aportaron una contribución señalada, según lo miraba él, a la maestría en la representación. 'El arte se elevó desde los humildes comienzos hasta la cumbre de la perfección.' Porque genios naturales como Giotto roturaron el terreno y así otros pudieron edificar sobre los primeros cimientos (Gombrich, 1982, p. 25).

Cuando Gombrich examina los supuestos del concepto de progreso de la historia del arte -de Plinio y Vasari- y los de la categoría de estilo de esta disciplina -como los de Heinrich Wölfflin-, trata problemas diversos como la crisis de dicho concepto de progreso, los cambios de percepción, y la articulación de tradiciones o estilos, que Thomas Kuhn igualmen- 
te ha trabajado al fundamentar no solo la discusión sobre el paralelismo entre ciencia y arte, sino su propia concepción estructural. Debió de haber llamado particularmente la atención de Kuhn la tesis de Gombrich basada en Karl Popper sobre la articulación de tradiciones, dado que se aproxima a la categoría de paradigma -que analizaremos más abajo-. Gombrich veía los estilos -o modos uniformes de representar al mundo en una época determinada- como la formación de tradiciones creadas por un "espíritu supraindividual", de manera comparable a como Kuhn veía a los paradigmas formados por "comunidades científicas". Cabe mencionar ahora el interés compartido de Ernst Gombrich y Thomas Kuhn en la obra de Karl Popper. Kuhn trata específicamente su aproximación a Popper en "Lógica del descubrimiento o Psicología de la Investigación": es un texto en el que yuxtapone aspectos coincidentes y divergentes con relación a la lógica del descubrimiento, a los procesos dinámicos por los cuales el conocimiento científico es adquirido, a la investigación en un contexto histórico, al rechazo a ver el progreso científico por incremento, la relación de la teoría y la observación científica según el mismo y conforme a Popper (Kuhn, 1970/1977). Igualmente existe concordancia entre Thomas Kuhn y Ernst Gombrich respecto de la naturaleza creativa de las actividades artística y científica y cómo ambos justifican el paralelismo de arte y ciencia en el Renacimiento al hablar sobre cómo Leonardo da Vinci y otros pintores pasaban indistintamente de una empresa a la otra y cómo los contemporáneos de da Vinci comentaban que en su vejez, cuando le molestaba pintar, se obsesionaba por la matemática como acto creativo (Gombrich, 1960/1982, p. 97).

Kuhn -como mencionamos anteriormente- debió haber estudiado también una conferencia que Gombrich presentó en el XVII Congreso Internacional de Historia del Arte, celebrado en Amsterdam "La concepción renacentista del progreso artístico y sus consecuencias" (Gombrich, 1952/1984) porque en esta ponencia analiza el concepto de progreso y el efecto que tuvo en la creación artística. Examinó la influencia de Plinio en el cambio de estilo de Ghiberti entre las primeras Puertas del paraíso (1403-1424) y las segundas puertas en el Baptisterio (1425-1452) en Florencia. Ghiberti cuenta un pasaje que había leído en Plinio sobre una competencia entre Apeles y Protógenes establecida para ver quién trazaba más finamente una línea, pero Ghiberti comenta que desde su punto de vista como artista lo que debió haber sucedido es una competición por hallar soluciones a un difícil problema de perspectiva. Ghiberti estaba convencido de que la tabla de Apeles debió haber mostrado la solución con la cual Protógenes se declaró vencido. Gombrich afirma que la enmienda de Ghiberti habla de la mentalidad influida por la idea de progreso y comenta cómo el artista trabaja como científico y cómo las obras de arte, por tanto, además de su propio interés pudieron haber trabajado soluciones a problemas, lo cual muestra el tipo de pensamiento de un artista y científico del Renacimiento, y piensa que la diferencia puede estribar en que las soluciones estudiadas por Ghiberti sean demostraciones que contribuyen al conocimiento. Gombrich señaló más adelante que los artistas románticos, nazarenos, y prerrafaelitas, habían cuestionado el criterio subyacente a la idea de progreso en el arte, según el cual la destreza determina una mejor obra de arte. El historiador británico también habla sobre la distinta interpretación de la historia del arte de Alois Riegl -respecto de la de Giorgio Vasari, en Las vidas de los artistas, y de la de Plinio en la Historia naturalporque había comenzado a poner en duda la concepción renacentista de progreso artístico. Esta interpretación debió parecer a Kuhn -más de lo que reconoció en La estructura de las revoluciones científicas- que contribuía a dilucidar su idea de modelos de desarrollo científico. Cabe recordar también la concepción renacentista del progreso artístico según las Vidas de los artistas de Vasari -de acuerdo con Gombrich-: la línea ascendente de las artes de lo primitivo a la perfección, de lo antiguo a lo nuevo, del "desastre gótico" al "pináculo del arte de Miguel Ángel", y el recorrido de las tres etapas «bueno», "mejor» y "superior».

Cinco años después de aparecida La estructura de las revoluciones científicas, la Sociedad para el estudio comparativo de historia y sociedad, de Cambridge University, organizó en Anne Arbor un foro de discusión multidisciplinario que trató, específicamente, el paralelismo entre ciencia y arte. Estuvo a cargo de los historiadores del arte James S. Ackerman, de Harvard University (Ackerman, 1969), Hafner E. M., de Hampshire College (Hafner, 1969), George Kubler, de Yale University (Kubler, 1969), y Thomas Kuhn, entonces profesor de Princeton University como historiador de la ciencia (Kuhn, 1969). La polémica en general hace reflexionar sobre la posibilidad de aplicación de la teoría de Thomas Kuhn en el estudio del arte, y muestra cómo algunos aspectos de la historia del arte han sido útiles en la comprensión de la naturaleza del fenómeno científico. En su conferencia titulada Comentarios sobre relaciones de ciencia y arte, Kuhn reconoce que el trabajo de Ernst Gombrich ha sido un estímulo para él, y señala que ciertos tópicos que él había trabajado en su estructuralismo de las 
revoluciones científicas, como los patrones de desarrollo, la naturaleza de la innovación creativa, el rol de las escuelas competidoras, las tradiciones inconmensurables y los modos alterados de percepción, han sido básicos para la historia del arte, mientras que, en su opinión, han sido exiguamente representados en escritos sobre ciencia. La participación de Kuhn en Anne Arbor se centró, más que en los problemas de las vanguardias tratados por Ackerman y Kubler, en aspectos fundamentales del paralelismo entre ciencia y arte, motivado por la oposición que al respecto había sido expuesta por Hafner. El profesor de Hampshire había comparado los trabajos de una selección de ejemplos científicos con obras de arte de la modernidad, el tipo de actividades de las que resultan esos trabajos, y el carácter esotérico con el que ciencia y arte aparecen ante el observador casual. Cabe señalar que extrañamente Hafner no vio en el esoterismo implícito en el cambio revolucionario sucedido durante el desarrollo del arte moderno la posibilidad de reestructuración de la percepción, que podría haber dado pie a una interesante discusión sobre la falta de acoplamiento entre la antigua forma de ver a la nueva -vanguardista- y la probabilidad subyacente de articulación de un cambio paradigmático. Kuhn señaló a Hafner el fracaso en el uso de las herramientas empleadas en ese tipo de análisis, la restringida selección y la descontextualización de los ejemplos, y afirmó que en ningún área el contraste entre ciencia y arte es más evidente que en el análisis de los problemas del progreso y la perdurabilidad en el arte; y concluyó que en su opinión es evidente que arte y ciencia son dos tipos de empresas muy diferentes, o cuando menos lo han sido desde el siglo XIX, principalmente porque la ciencia, a diferencia del arte, destruye su pasado (Kuhn, 1969, pp. 403-407 y p. 412).

Por otra parte, Kuhn consideró acertada -aunque irrelevante en relación con los temas tratados- la disertación de Kubler sobre el carácter etológico del estructuralismo de las revoluciones científicas con el objeto de poner puntos de comparación entre el comportamiento de las comunidades científica y artística (Kubler, 1969). Al respecto, Kuhn abundó sobre algo que para él era extremadamente importante: cómo el comportamiento humano de la comunidad científica y la comunidad artística son parte integrante de la construcción de ambas empresas. Por otra parte, lo que pareció a Kuhn más interesante del análisis de Kubler es la discordancia de las categorías paradigma y estilo, dada su pertenencia a diversas magnitudes. Al respecto Kuhn hizo una disertación -de especial interés para nuestra investigación- sobre la aplicación de modelo de paradigma en el estudio del fenómeno artístico. Kubler había interpretado que Kuhn -quien había definido paradigma como "[...] realizaciones científicas universalmente reconocidas que, durante cierto tiempo, proporcionan modelos de problemas y soluciones a una comunidad científica" (Kuhn, 1995, p. 13)- delimitaba paradigma como "teorías mayores", que permitían predicciones por su articulación cuantitativa: Kubler afirmaba que Kuhn deliberadamente había negado una mayor elasticidad al enfoque paradigmático de planes de investigación y que, por contraste, el concepto de estilo era muy elástico (Kubler, 1969). El propio Kuhn, sin embargo, replicó nunca haber hecho tal delimitación, y agregó algo que para nuestra investigación ha sido fundamental:

Por lo contrario, doy especial importancia a esos conceptos que permiten una más completa comprensión del extraño carácter no-acumulativo de los eventos como el descubrimiento del oxígeno, de los rayos $X$, o del planeta Urano. Más importante, los paradigmas no deben ser enteramente igualados con teorías. Más fundamentalmente, ellos son ejemplos concretos aceptados de realización científica, soluciones a problemas que los científicos estudian con cuidado y sobre los cuales ellos modelan su propio trabajo. Si la noción de paradigma puede ser útil al historiador de arte, serán imágenes no estilos lo que sirve como paradigmas. [...] Ambos 'estilo' y 'teoría' son términos usados cuando se describe un grupo de trabajos que se reconocen similares. (Ellos están 'en el mismo 'estilo' o son 'aplicaciones de la misma teoría'). En ambos casos se prueba la dificultad-yo pienso ultimadamente imposibilidad- para especificar la naturaleza de los elementos compartidos que distinguen a un estilo dado o a una teoría dada de otra. Mi respuesta a tales dificultades ha sido sugerir que los científicos pueden aprender de paradigmas o modelos aceptados sin ningún proceso como la abstracción de elementos que pueden constituir una teoría. ¿Puede algo de esta clase ser dicho de la manera en que los artistas aprenden a examinar trabajos de arte particulares? (Las cursivas son nuestras) (Kuhn, 1969, p. 412).

Thomas Kuhn está afirmando textualmente que es posible trabajar estudios sobre arte en el contexto de la articulación de paradigmas según el estructuralismo de las revoluciones científicas aun cuando, desde el S. XIX, ciencia y arte han sido empresas de distinta naturaleza, dado que ciencia desecha su pasado a diferencia del arte, pero que son imágenes y no estilos lo que sirve como paradigma. En esta declara- 
ción también trata el extraño carácter no acumulativo de las revoluciones científicas: el tipo de episodio en el cual deja de agregarse conocimiento a lo que era conocido; no acostumbrado en las teorías de estilos según Heinrich Wölfflin (1924/1985), Erwin Panofsky (1936/2000), Meyer Shapiro (1962/1994) o, entre otros, Ernst Gombrich (1968/1998)..., pero que es lo que nos ha llevado a confirmar que el cambio habido en 1907-1915 -que involucra imágenes producidas en el ámbito del cubismo, pero también en el de las vanguardias aledañas como el futurismo, el dadaísmo, el neoplasticismo, el conceptualismo de Duchamp, el abstraccionismo de Kandinsy y el suprematismo- es de carácter revolucionario porque entonces comienzan a producirse obras enteramente contrarias e incompatibles con las del paradigma anterior. El tipo de obras que, probablemente, podrían no haber sido percibidas como arte por los artistas del paradigma anterior; pero, lo que es más sorprendente, durante un lapso revolucionario, no son percibidas como arte por quienes están inmersos en el cambio -que Kuhn distingue como tensión esencial- y describe como: "episodio de carácter no acumulativo". Entre 19071915 hay intervalos durante los cuales los propios artistas -Picasso, Kandinsky, Duchamp, Mondrian, Malevich...-dudan de su propia creación, dada la distinta concepción del arte en la que habían sido formados previamente: "Picasso sentía un cierto desasosiego afirma André Salmon-. Ponía sus telas contra la pared y arrojaba al suelo los pinceles. [...] se trataba de un cuadro [Las Señoritas de Avignon (1907)] nunca expuesto al público. Son problemas desnudos, números blancos sobre un fondo negro." (Salmon, 1912/1995). Marcel Duchamp piensa no estar trabajando obras de arte y no formula la idea de los ready-mades hasta dos años después de haber creado Rueda de bicicleta (1913) y Portabotellas (1914), cuando estos ya habían desaparecido. Su hermana Suzanne, quien también era una artista, al no reconocer las piezas como obras de arte, las había echado a la basura (Tomkins, 1999, pp. 150-153 y p. 177). Malevich fue despedido del Moscow Institute of Painting, Sculpture, and Architecture, encarcelado e interrogado por su obra suprematista, después de lo cual deja de pintar abstracciones e inicia un periodo de combinaciones abstractas y figurativas [son combinaciones en las que vuelve a pintar el horizonte] (Drutt, 2003, p. 16). Es entonces cuando las obras ya no pueden ajustarse a los términos acostumbrados y, para denominar a sus obras, tienen que crearse nuevas expresiones: Vassily Kandinsky puede titular a sus paisajes Murnau. El jardín I (1910), Winter II (1912), pero también Improvi- sación 7 (1910); Piet Mondrian los nombra Muelle y Océano 1-IV (1914), tanto como Composición 10 en negro y blanco (1915); Marcel Duchamp cuestiona si es posible hacer obras que no sean de arte (Duchamp, $1913 / 1978)$ y denomina sus trabajos retardos, readymades, ready-mades ayudados, dada la convicción que tiene de estar trabajando en un campo que ya no es el del arte tal y como había sido entendido hasta entonces por la comunidad artística (Tomkins, 1999, pp. $150-153$ y p. 177). Todo ello concuerda con la forma en que Kuhn describe los cambios de tipo revolucionario: "Los cambios revolucionarios son diferentes y bastante más problemáticos. Ponen en juego descubrimientos que no pueden acomodarse dentro de los conceptos que eran habituales antes de que se hicieran estos descubrimientos. Para hacer, o asimilar, un descubrimiento tal, debe alterarse el modo en que se piensa y describe un rango de fenómenos naturales" (Kuhn, 1987/1996, p. 59).

\section{EL ESTADO ESOTÉRICO O INVISIBILIDAD DEL PAI- SAJISMO MODERNO Y CONTEMPORÁNEO VISTO A TRAVÉS DEL ESTRUCTURALISMO DE LAS REVOLUCIO- NES CIENTÍFICAS DE THOMAS KUHN}

Thomas Kuhn, al analizar el problema de la invisibilidad de las revoluciones científicas, trata la cuestión de la depreciación de los hechos históricos en la ideología de la profesión científica. Piensa, desde una perspectiva historiográfica, que hasta poco antes de mediados del siglo pasado la comunidad científica no comenzó a tener otro tipo de fuentes además de la práctica científica, e identifica entre ellas los libros de texto, las obras de divulgación y la filosofía de la ciencia. La invisibilidad de las revoluciones científicas en estos estudios sobre ciencia, de acuerdo con Kuhn, se debe principalmente a que estas fuentes básicamente se dirigen a un cuerpo ya articulado de problemas, datos y teorías de su propio paradigma y no cambian la estructura de los mismos. Kuhn, por contraste con dichas fuentes, no solo analiza los distintos paradigmas relativos a la historia de la ciencia, sino que se extiende sobre la historia de otras disciplinas -entre ellas la historia del arte- (Kuhn, 1995, pp. 212-216). Ello es evidente en su interés sobre la concepción histórica del fenómeno artístico desde el Renacimiento, en la obra de Ernst Gombrich particularmente y en su participación en el foro de discusión multidisciplinario sobre ciencia y arte en Cambridge University.

De manera comparable tratamos de comprender por qué la historia del arte difícilmente ha visto paisajismo en ciertas obras posteriores al cambio revolucionario que son estudios visuales sobre la natura- 
leza y las ciudades, aunque plasmados en una Gestalt visual enteramente distinta -permanecen en estado esotérico, diría Kuhn- en tanto que conforman la articulación de un cambio paradigmático. Estudios como los de Malcolm Andrews (1999, pp. 25-51) Anna María Guasch (2002, p. 51) Jeffrey Kastner y Brian Wallis (Kastner y Wallis, 1998, p. 1) o, entre otros ejemplos, Michael Lailach (Lailach, 2007, p. 7) han tratado estos estudios visuales como paisajismo, pero básicamente a partir de la década de los años sesenta del siglo pasado en el contexto de las nuevas vanguardias más naturalistas como Land Art o Earth Art, pero no en las obras de los movimientos abstractos, del arte povera, del arte conceptual, del neo-expresionismo alemán o, entre otros, del arte de los nuevos medios digitales; nos referimos a trabajos como Train Landscape [Tren paisaje] (1953) Ellsworth Kelly; Ocean Park No. 45 [Parque Océano No. 45] (1971) Richard Diebenkorn; Entrare nell'opera [Entrar en la obra] (1970) Alighiero Boetti; Inert Gas: Helium [Gas inerte: helio] (1969) Robert Barry, en Desierto Mojave; Studio: Interiors, Buildings, Parks [Estudio: Interiores, Edificios, Parques] (2004), de Vito Acconci.

La historia del arte del vanguardismo, como es sabido, se estudia preeminentemente en antologías cuya función ha sido compilar e interpretar tipos diversos de documentación sobre arte, a fin de aproximarnos a comprender la suma de vanguardias históricas y nuevas en el contexto de las antítesis autonómicas de cada movimiento. Esto concuerda con la percepción de Hans Belting de la separación de la historia del arte de las prácticas vanguardistas: una historia del arte que supone ver, desde una clase de avanzada scout, las prácticas artísticas del pasado y no a sus contemporáneas (Belting, 1987, pp. 12-13). Por otra parte, no todos han percibido un cambio revolucionario, y quienes como John Golding o John Berger lo han hecho, no lo han comprendido como un cambio de carácter no acumulativo comparable con lo tratado por Kuhn con los historiadores del arte en el foro de discusión multidisciplinario de Anne Arbor. Obras como Documentos para la comprensión del arte moderno, de Walter Hess; Las vanguardias artísticas del siglo $X X$, de Mario de Micheli; Escritos de arte de vanguardia 1900/1945, de Ángel González, Francisco Calvo y Simón Marchán; Movements in art since 1945, Edward Lucie-Smith; Del arte objetual al arte de concepto, de Simón Marchán; El arte último del siglo XX, de Anna María Guash; antologías de documentos como Teorías del arte contemporáneo, de Herschel Chipp o, entre otros, Theories and Documents of Contemporary Art, de Stiles y Selz, son textos fundamentales para el estudio del vanguardismo histórico y nuevo y, en ese sentido, hay que agregar la inmensa producción de estudios monográficos como Russian Art of the Avant Garde. Theory and Criticism, editado por John E. Bowlt; Land and Environmental Art, por Jeffrey Kastner y Brian Wallis; o de a cada género Performance Art. From Futurism to the Present, de RoseLee Goldberg; Digital Art, por Christiane Paul; o Beyond New Media Art de Domenico Quaranta...; sin embargo, un estudio sobre el cambio epistémico y paradigmático, como el que ha habido entre 1907-1915, no está completamente presente en el campo de visión de esta suma de estos textos. El estudio de la obra de Piet Mondrian, por ejemplo, en diversas ocasiones ha sido dividido en dos épocas: la fracción oscila entre 1911 y 1914. Cada parte es analizada por distintos grupos de investigadores como si ambos segmentos no correspondiesen a un mismo artista, y difícilmente se procura conocer la naturaleza del cambio habido en este pintor holandés: Roever, por ejemplo, publica investigaciones sobre la obra de Mondrian previa al cambio revolucionario: Amsterdam Years, 1892-1912. El cambio en general se atribuye al vanguardismo en su conjunto. Pero hay análisis más precisos que ven un cambio revolucionario en el cubismo. Otros vemos un cambio revolucionario de forma articulada entre el cubismo y vanguardias asociadas a este. Hay quien define la revolución como aceleración. Nosotros la definimos como etapa no acumulativa. Finalmente, apuntamos que hay pocos estudios específicos sobre la naturaleza de los descubrimientos, los inventos evidentes en las obras de referencia. Piet Mondrian (1995-1996), Museo de Arte Moderno de Nueva York, muestra la obra posterior a 1908; Piet Mondrian and The Hague School of Landscape Painting (1969), Norman Mackenzie Art Gallery, Regina, la obra anterior a 1908. Simon Schama, por contraste, en La auténtica cuadrícula: para entender a Mondrian lamenta la falta de la primer época en la muestra del MOMA (Schama, 2002, p. 129) y precisa el cambio de la representación a la abstracción de esta manera: "Es imposible imaginarse un documento más poderoso de su conversión de la percepción a la visión que el de Pier and Ocean de la serie 1914-1915 [...]" (Schama, 2002, p. 129); en ese mismo sentido Harry Holtzman comenta que la incomprensión del cambio de estructura en la obra de Mondrian comienza con la obra cubista (Holtzman, 1944/1945, p. 8).

$\mathrm{Si}$, como afirma Thomas Kuhn, lo que cambian son los hechos y las teorías (Kuhn, 1995, p. 219), y como argumenta en Harvard University son las imágenes y no los estilos lo que sirve de paradigma, entonces las 
obras, de manera particular, primordialmente se pueden estudiar en los catálogos razonados que, como es sabido, incluyen cada una de las imágenes como Piet Mondrian. Catalogue Raisonné I; Piet Mondrian. Catalogue Raisonné II-III, de Joop M. Joosten; Marcel Duchamp, de Anne d'Harnoncour y Kynaston McShine; Pablo Picasso, de Christian Zervos; El cubismo de Picasso. Catálogo razonado de la obra pintada, 19071916, por Pierre Daix y Joan Rosselet. ${ }^{4}$ Un análisis de ajuste al catálogo de Zervos como Picasso en Gósol, 1906: un verano para la modernidad de Jèssica Jaques $\mathrm{Pi}$, tiende a ver un cambio paradigmático en el contexto de obra trabajada en Gósol, por Picasso (Jaques, 2007, pp. 17-20). El estudio de la secuencia de cada una de las imágenes de la comunidad artística puede llevar a examinar un cambio epistémico y paradigmático, más que la secuencia de vanguardias históricas.

Una comunidad de autores entre los que se encuentran John Berger, Peter Selz y Joshua C. Taylor, Ángel González, Calvo Serraller y Simón Marchán Fiz siguen una idea comparable con la de John Golding de que el cubismo es el movimiento revolucionario más importante e indudablemente más completo desde el Renacimiento. Desde el punto de vista estrictamente visual, Golding piensa que es más fácil tender un puente entre los trescientos años que van del impresionismo y el Alto Renacimiento que sobre los cincuenta que separan el impresionismo del cubismo (Golding, 1993, p. 21). Golding ha concebido al cambio revolucionario como aceleración, a diferencia de nosotros que, con base en el estructuralismo de Kuhn, lo vemos como un episodio de carácter no acumulativo en el cual deja de agregarse conocimiento y se inicia una nueva forma contraria e incompatible con la anterior que, como hemos visto, caracteriza un cambio paradigmático. Entre los estudios de carácter transhistórico: "El ícono invisible o el ícono de lo invisible. Antonello y los nuevos paradigmas en la pintura renacentista" (2011) Hans Belting percibe al estudiar de imagen a imagen que este pintor ha reinventado un sistema visual desde cero y, aun sin referirse al estructuralismo de Kuhn, concuerda en que un cambio paradigmático como el habido entre el ícono bizantino y la imagen renacentista debiese ser irreconciliable, lo que concuerda con nuestra concepción de cambio paradigmático.

La articulación del paradigma es menos problemática: John Berger, por ejemplo, piensa que la dinámica de la revolución cubista está en cierta forma presente hacia la segunda mitad del siglo XX: "Encuentro difícil de creer que los trabajos cubistas más extremos fueran pintados hace más de cincuenta años. Es verdad que no podría esperar que fuesen pintados hoy. Son muy optimistas y revolucionarios para eso" (Berger, 1969/2002, p. 71). Joseph Kosuth acepta -de acuerdo con Duchamp-que la función del arte es cuestionar la naturaleza del arte: definir la identidad del arte mediante la tautología. Igualmente reconoce que este cambio en parte viene de Monet, Cézanne y el cubismo- y esa identidad consiste en el remplazo de lo que se dice -parafraseando a Ludwig Wittgenstein- por la forma del lenguaje (Kosuth, 1969). Robert Smithson -en "An Interview with Robert Smithson" por Moira Roth-distingue la obra de Duchamp como una de las influencias fundamentales en el arte la época: "En un sentido el Armory Show es el comienzo de dos corrientes que puedo decir han desarrollado el arte en este país: una, modernidad-digamos [Paul] Cézanne y en esa área puede ser [Henri] Matisse-y por otra parte, posmodernidad, que es Duchamp" (Smithson y Roth, 1973/2004, p. 82). Duchamp piensa, en 1967, que las cosas han sucedido cuarenta años después de los descubrimientos y que ello debió haber molestado a la gente (Cabanne, 1987, p. 17). Peter Bürger -en Teoría de la vanguardia- trabaja sobre la restauración de la categoría de obra, la autonomía de la obra de vanguardia y analiza el origen histórico del vanguardismo ante el hecho inminente de que una nueva época ha comenzado: "[...] hoy -escribe Bürger-se producen intentos de continuar la tradición de los movimientos de vanguardia, pero tales intentos, como por ejemplo los happenings -que podríamos llamar neovanguardistas- ya no pueden alcanzar el valor de protesta de los actos dadaístas, independientemente de que puedan ser planteados y llevados a cabo con una mayor perfección (Bürger, 1987, p. 114). Posteriormente Hal Foster ve deslizamientos de las vanguardias históricas en las nuevas vanguardias, pero al mismo tiempo ve discrepancia con los deslizamientos de paradigmas según el estructuralismo de Kuhn y piensa que hay poco en común entre innovación artística y revolución científica (Foster, 2001, p. X). Peter Bürger tampoco ve revolución en el cubismo, aunque si en el dadaísmo dada su praxis vital. No son todos los autores, pero son suficientes para mostrar que en la discusión teórica del arte de la segunda mitad del siglo pasado hay ideas sobre los pocos desacuerdos habidos entre las obras de esa época y las de las vanguardias históricas o de la modernidad. Todos estos autores se aproximan a afirmar que en los movimientos artísticos de la segunda mitad del siglo pasado son paradigmáticos de los planteamientos de los vanguardistas históricos, aunque ningún caso ve la transformación revolucionaria por sí misma, el cambio de carácter no acumulativo habido entre 1907-1915. 
Estos diferentes movimientos -pop art, arte povera, arte conceptual, arte mínimal, op art...- son comparables con el tipo de cambio normal en el modelo de Kuhn, en el que cambian partes de forma innovadora, mientras que el resto del sistema permanece: "Pero el desarrollo científico -escribe Kuhn- manifiesta también una modalidad no acumulativa y, los episodios que la exhiben proporcionan claves únicas de un aspecto central del conocimiento científico" (Kuhn, $1987 / 1996$, p. 57). El cambio revolucionario, por contraste, sucede de manera holista en una fracción de siete $u$ ocho años entre la comunidad artística. De acuerdo con Kuhn, en su análisis del cambio paradigmático de la mecánica según Aristóteles a la mecánica según Newton, sucede un cambio súbito que reordena toda la estructura conceptual y visual y los científicos se sienten como transportados a otro mundo; lo cual no es motivo para concluir la inexistencia de la mecánica aristotélica, sino su pertenencia a otro paradigma.

Hay que problematizar estos episodios y ver, precisamente, que cierta comunidad de artistas deja de trabajar sobre la concepción de arte conocida hasta entonces. El año en el que crea Rueda de bicicleta, Marcel Duchamp se pregunta: "¿Se pueden hacer obras que no sean de «arte»?" (Duchamp, 1913/1978); además, durante un lapso de dos años él mismo no consigue ver como obra ese y otros ready-mades como Portabotellas (1914); asimismo su hermana Suzanne -quien también era una artista- tampoco tiene elementos teóricos ni visuales para reconocer estos trabajos como obra y, en consecuencia, se deshace de ellos; es decir que Duchamp no puede denominar a estas obras como "arte» (Tomkins, 1999, pp. 150152 y p. 177). Por otra parte, André Salmon habla del desasosiego de Pablo Picasso, de cómo acostumbra voltear Las señoritas de Avignon contra el muro, de la desilusión del público, y su descripción del cuadro revela un cambio de percepción visual y conceptual que se manifiesta en su lenguaje como crítico: "Son problemas desnudos, números blancos sobre fondo negro." (Salmon, 1912/1995). La obra suprematista de Kasimir Malevich es depreciada por el Moscow Institute of Painting, Sculpture, and Architecture; Malevich es denunciado por esta institución -que era su lugar de trabajo-, pronto fue despedido y encarcelado (Drutt, 2003). Se conoce por las memorias de Mies Elout-Drabbe que, en octubre de 1914, Piet Mondrian estaba de tal manera absorto en su lugar de trabajo, que ni siquiera advirtió el arribo de miles de refugiados belgas a la isla Walcheren, dado el inicio de la primera guerra mundial. Entonces dibuja los bocetos -comentados por Shama- de la serie Muelle y Océano I-IV y los de las noches estrelladas (Joosten, 1998). Todos estos no son sucesos aislados, sino la articulación de un episodio de carácter no acumulativo entre la comunidad artística. Por una parte, van renunciando completamente a la concepción del arte en el cual se habían formado, y por otra, van descubriendo, inventando formas de pensar el fenómeno artístico contrarias e incompatibles con lo anterior -y los estudios visuales sobre la naturaleza y las ciudades son un segmento de estas transformaciones-. Kuhn analiza el comportamiento que artistas y científicos tienen como respuesta a las crisis, que les lleva a cambios revolucionarios: "Cómo los artistas, los científicos creadores deben ser capaces de vivir, a veces, en un mundo desordenado; en otro lugar, he descrito esta necesidad como la "tensión esencial" implícita en la investigación científica" (Kuhn, 1995, p. 130). Esta "tensión esencial" básicamente implica que la comunidad científica abandona la forma aceptada de ver el mundo, a favor de otra, usualmente incompatible, de aproximarse a su disciplina (Kuhn 1959/1977, pp. 225-226).

Si estamos de acuerdo con Kuhn cuando trata los cambios de concepción del mundo asociados a cambios de paradigmas entonces podremos ver paisajismo en los estudios visuales sobre la naturaleza y las ciudades posteriores al cambio revolucionario: “[...] durante las revoluciones los científicos ven cosas nuevas y diferentes al mirar con instrumentos conocidos y en los lugares en donde ya habían buscado antes" (Kuhn, 1995, p. 176). Pablo Picasso, Vassily Kandinsky, Piet Mondrian y Kasimir Malevich seguían haciendo estudios visuales sobre la naturaleza y las ciudades al tiempo de su conversión hacia la abstracción, tanto como Duchamp lo siguió haciéndolo en su conversión al pensamiento conceptual: es decir que el componente -o tema de la pintura o de la obra-, no ha desaparecido, sino que se plasma en otro sistema Gestalt visual distinto del anterior y que ha determinado un marco de investigación durante un tiempo digno de consideración.

\section{CONCLUSIONES}

El estructuralismo de las revoluciones científicas, según Thomas Kuhn, es una construcción de la historia de las ciencias capaz de llevar a pensar la articulación de cambios paradigmáticos en historia del arte. En el fenómeno artístico hay evidencia de cambios de tipo revolucionario que, como hemos mostrado, implican episodios de carácter no acumulativo y también la hay de cambios de carácter normal en que las comunidades artísticas trabajan de manera acumulativa y altamente 
especializada sobre los supuestos revolucionarios. "El regresó a París después de la guerra -escribe Robert Motherwell sobre Piet Mondrian-, publicó Le NeoPlasticisme (1920), y se dedicó a pintar, viviendo mes tras mes en increíbles pequeñas sumas" (Motherwell, 1945 , p. 6). La comunidad artística que, por otra parte, sucede a este cambio, toma como modelo durante una importante cantidad de tiempo los ejemplos iniciales resultantes de las transformaciones de 1907-1915; todo lo cual nos lleva a pensar en la probabilidad de constatar la articulación de un nuevo paradigma o paradigmas compartidos en las artes visuales y no solo enunciar la promesa. A diferencia del fenómeno científico cuyas comunidades tienden a aceptar un paradigma dominante, el fenómeno artístico se ha desenvuelto de forma tal que puede ser interpretado como una articulación de paradigmas compartidos. Cesar Lorenzano ha comparado este fenómeno con la etapa pre-paradigmática de escuelas competidoras en el modelo de Kuhn (Lorenzano, 1982, p. 86).

Anselm Kiefer, por ejemplo, piensa su propia identidad con relación a un paradigma en estos términos: "Kandinsky estaba conectado con Brücke [Puente] y el Blue Reiter [Jinete azul]: ellos tienen el concepto y crearon una realidad. Pero yo prefiero a Fautrier con su sufrimiento y ensimismamiento. Y su propósito en traer cambios era fuerte. Como resultado veo en Fautrier un paradigma más fuerte que Kandinsky" (Kiefer 1985/1996, p. 61). Como artista Kiefer puede dar forma a este enunciado, dado que no entra en el campo de la constatación, a diferencia de la historia del arte o los estudios sobre arte. Se siente atraído por el tema abordado en la pintura y la escultura de Jean Fautrier, al compartir con él su aflicción por el trauma de la guerra, pero la obra misma de Fautrier -como los
Otages [Rehenes]- es paradigmática del cambio revolucionario de principios de siglo pasado: el informalismo agrega conocimiento al arte abstracto que viene de esas transformaciones iniciales. El componente no cambia: los desastres de la guerra son compartidos por Francisco de Goya y Lucientes, Jean Fautrier y Anselm Kiefer: lo que ha cambiado completamente entre el primero y los segundos es la concepción del arte y, por tanto, se ha transformado la Gestalt visual que los caracteriza. Trabajos como La cauterización del distrito rural de Buchen (1974) de Kiefer, que hace referencia del paisaje alemán completamente quemado al término de la guerra, difícilmente puede verse en el contexto del paisajismo si no se altera la forma de pensar las artes visuales y el paisajismo como un segmento de estas, y se experimenta, en consecuencia, un cambio de percepción del sistema de la imagen.

Finalmente, además de distinguir que Thomas Kuhn hizo estudios sobre historia del arte con especial interés en Ernst Gombrich -lo que fundamenta la realización de estudios sobre historia de la ciencia desde la historia del arte o los estudios sobre arte-, destacamos que frente la labor alcanzada por la historia del arte, Kuhn llega a percibir que los estudios sobre ciencia hasta hace poco no tenían otra fuente que no fuese la práctica científica.

Este enfoque interpretativo sobre los estudios visuales de la naturaleza y las ciudades trata de vincularse con investigaciones más recientes como Simon Schama, Landscape and Memory (1996), Whiston Spirn, The Language of Landscape (1998), Mitchel, W. J. T., Landscape and Power (2002), Edward Casey, Earth-Mapping. Artists Reshaping Landsape (2005), o James Elkin, Landscape (2008).

\section{NOTAS}

1. Jean Metzinger y Albert Gleizes en su libro Cubismo (1912/1995) se ocupan de este cambio epistémico: "Sobre todo, que nadie se deje engañar por la apariencia de objetividad con que muchos artistas imprudentes dotan a sus cuadros. No hay forma directa de valorar los procesos gracias a los cuales las relaciones entre el mundo y el pensamiento se nos hacen perceptibles. Lo que habitualmente se invoca, el encontrar en un cuadro las familiares características que motivan la forma, no prueba nada en absoluto. Imaginemos un paisaje. La anchura de un río, la espesura del follaje, la altura de las orillas, las dimensiones de cada objeto, son garantías seguras.
Bien; si las encontramos intactas en la tela no habremos aprendido nada acerca del talento o el genio del pintor. El río, el follaje, las orillas, pese a la cuidadosa representación de sus proporciones, ya no 'dicen' nada por su anchura, espesor y altura, ni por las relaciones entre esas dimensiones. Sacado todo ello de su espacio natural, han pasado a formar parte de otra clase de espacio, el cual no asimila las proporciones observadas. Son algo externo. Tienen la misma importancia que el número de un catálogo, que un título al pie de un cuadro. Discutir esto es negar el espacio del pintor; es negar la pintura misma." (Las cursivas son nuestras) (Metzinger y Gleizes, 1912, p. 226). Picasso, por su parte, afirma: "Dos problemas se presentan a mi espíritu. Observo que la pintura tiene valor por sí misma, independientemente de la representación objetiva de las cosas. Me pregunto si no debemos pintar las cosas como las conocemos, más bien que como las vemos" (Zervos, 1932-1978. Tomado de Hess 1984, p. 74)

2. César Lorenzano ha trabajado una teoría del arte que puede ayudarnos en la comprensión del problema epistemológico que plantea la tesis cubista. Este filósofo argentino se propuso incorporar un estructuralismo genético y evolutivo, basado en la teoría del conocimiento de Jean 
Piaget, para analizar el fenómeno artístico. Circunscribe el universo de la producción artística entre los polos naturalismo - abstracción, de manera similar a como lo había hecho Herbert Read en Filosofía del arte moderno. Lorenzano considera en su estructura que toda la gama de combinaciones posibles de la creación artística se encuentra en la tensión creada por los polos realista [o naturalista] y abstracto. Su definición de arte versa de la siguiente manera: "[...] la obra de arte es la construcción de un objeto donde se exteriorizan las estructuras cognoscitivas, representativas, simbólicas. Es la objetivación de estructuras objetivas que son producto del trabajo humano (Lorenzano, 1982, p. 25).

3. "Como consecuencia de ello, a finales de los años sesenta, en Estados Unidos y en Europa se empezó a obviar el es-

\section{BIBLIOGRAFÍA}

Ackerman, J. S. (1969). The Demise of the Avant Garde: Notes on the Sociology of Recent American Art. Comparative Studies in Society and History. An International Quarterly, 11, 4, pp. 404-424. https:// doi.org/10.1017/s0010417500005430

Andrews, M. (1999). Landscape and Western Art. Oxford, New York: Oxford University Press.

Belting, H. (1987). The End of the History of Art. Chicago, London: The University of Chicago Press.

Belting, H. (2009). Looking through Duchamp's Door. Art and Perspective in the Work of Duchamp. Sugimoto. Jeff Wall. Köln: Walther König.

Belting, H. (2010). La inoportuna herencia de la modernidad: el estilo y la historia. En Belting, H. La historia del arte después de la modernidad. México: Universidad Iberoamericana, pp. 45-56.

Belting, H. (2011). El ícono invisible y el ícono de lo invisible. Antonello y los nuevos paradigmas en la pintura renacentista. En Belting, H. La imagen y sus historias: ensayos. México: Universidad Iberoamericana, pp. 29-45.

Berger, J. (1969/2002). The Moment of Cubism. En Dyer, G. (ed.). John Berger. Selected Essays. Nueva York: Random House, Vintage International.

Boccioni, U. (1994). Contra el paisaje y la vieja estética. En Boccioni, U. Estética y arte futuristas: dinamismo plástico. Barcelona: El Acantilado, pp. 16-24. pacio del taller, de la galería, del museo e incluso el de la ciudad, con la voluntad de convertir el paisaje natural en medio y en lugar de la obra de arte. Así se fue configurando el Earth Art, conocido también como Land Art. El término Earth Art, que se puede traducir como "arte de la tierra» en tanto que manipulación de obras aisladas o reunidas en conjuntos abarcables que se realizan con materiales procedentes de la tierra (tierra, piedras, troncos y hojas de árboles, pétalos de flores, etc.), fue utilizado inicialmente por los artistas norteamericanos, mientras que las manifestaciones europeas de este tipo se agruparon bajo la denominación de Land Art. En este caso, sin embargo, el concepto de tierra, o mejor, de naturaleza, no se concibe como un lugar proveedor de materiales, sino como soporte que se

Bordieu, P. (1995). Free Exchange. Pierre Bordieu and Hans Haacke. Stanford University Press.

Bowlt, J. (1991). Russian Art of the Avant Garde. Theory and Criticism, 19021934. London: Thames and Hudson.

Bürger, P. (1987). Teoría de la vanguardia. Barcelona: Península.

Cabanne, P. (1987). Dialogues with Marcel Duchamp. Da Capo Press.

Casey, E. (2005). Earth-Mapping. Artists Reshaping Landscape. Minneapolis, London: University of Minnesota Press.

Chipp, H. (1995). Teorías del arte contemporáneo. Fuentes artísticas y opiniones críticas. Madrid: Akal.

Clark, K. (1997). Landscape into Art. Nueva York: Icon Editions.

Daix, P. y Rosselet, J. (1979). El cubismo de Picasso. Catálogo razonado de la obra pintada, 1907-1916. Barcelona: Blume.

D'Harnoncourt, A. y McShine, K. (eds.). (1989). Marcel Duchamp. Nueva York, Philadelphia: The Museum of Modern Art, Philadelphia Museum of Art, Prestel.

Drutt, M. (ed.) (2003). Kazimir Malevich: Suprematism. En Kazimir Malevich: Suprematism. Nueva York: The Solomon R. Guggenheim Foundation.

Duchamp, M. (1913/1978). En Infinitivo. En Duchamp, M. Marcel Duchamp. Escritos: Duchamp du Signe. Barcelona: Gustavo Gili. manipula o se altera para producir una acción de carácter artístico. A tenor de ello, la expresión Land Art podría traducirse como "arte del paisaje», aunque en este caso entraría en conflicto con el tradicional género del paisaje (landscape), o como "arte de la naturaleza»." (Guasch, 2002).

4. Algunos de estos catálogos concuerdan con la datación del cambio 1907-1915 y en ellos es posible verificar precisamente obra a obra los cambios de forma Gestalt visual relativos a la introducción del pensamiento abstracto y del pensamiento conceptual por esta comunidad artística, cuyo descubrimiento es la base del cambio paradigmático de principios de siglo pasado: el paradigma surge, entre otros aspectos, del hecho de ese cambio epistémico.

Elkin, J. (ed.). (2008). Landscape. Nueva York, London: Routledge.

Foster, H. (2001). El retorno de lo real. La vanguardia a finales de siglo. Madrid: Akal.

Goldberg, R. (1988). Performance Art. From Futurism to the Present. London: Thames and Hudson.

Golding, J. (1993). El cubismo. Una historia y un análisis. Madrid: Alianza.

Gombrich, E. (1950/1984). La teoría del arte renacentista y el nacimiento del paisajismo. En Gombrich, E. Norma y forma. Madrid: Alianza, pp. 227-248.

Gombrich, E. (1952/1984). La concepción renacentista del progreso artístico y sus consecuencias. En Gombrich, E. Norma y forma. Madrid: Alianza, pp. 13-30.

Gombrich, E. (1968/1998). Style. En Preziosi, D. (1998). The Art of History: A Critical Anthology. Oxford University Press, pp. 150-163.

Gombrich, E. (1960/1982). Arte e ilusión. Estudio sobre la psicología de la representación pictórica. Barcelona: Gustavo Gili.

González García, A. (ed.). (2004). Leonardo da Vinci. Tratado de la pintura. Madrid: Akal.

González, García, A., Calvo Serraler, F. y Marchán Fiz, S. (2009). Escritos de arte de vanguardia 1900/1945. Madrid: Istmo.

Grasskamp, W., Nesbit, N. y Bird, J. (2004). Hans Haacke. London, New York: Phaidon. 
Guasch, A. M. (2002). El arte último del siglo XX. Del posminimalismo a lo multicultural. Madrid: Alianza.

Hafner, E. M. (1969). The New Reality in Art and Science. Comparative Studies in Society and History. An International Quarterly, 11, 4, pp. 385-397. https:// doi.org/10.1017/S0010417500005442

Hess, W. (1984). Documentos para la comprensión del arte moderno. Buenos $\mathrm{Ai}$ res: Nueva Visión.

Holtzman, H. (1944/1945). Introducción. En Mondrian, P. (ed.). Plastic Art and Pure Plastic Art 1937 and other essays, 19411943. New York: Wittenborn Art Books.

Jaques, P. (2007) Picasso en Gósol, 1906: un verano para la modernidad. Madrid: La Balsa de la Medusa.

Joosten, J. (1998). Piet Mondrian: catalogue raisonné (vol. 2 y 3). München, New York: Prestel.

Kastner, J. (ed.). (2012). Nature. Documents on Contemporary Art. Cambridge, Massachusetts: The MIT Press.

Kastner, J. y Wallis, B. (1998). Land and Environmental Art. London: Phaidon.

Kiefer, A. (1985/1996). Structures are No Longer Valid. En Stiles, K. y Selz, P. (eds). Theories and Documents of Contemporary Art. A Source of Artists'Writings. Berkeley, Los Angeles, London: University of California Press.

Kosuth, J. (1969). Art after Philosophy. En Harrison, Ch y Wood, P. (eds.) (2002). Art in Theory 1900-2000. An Anthology of Changing Ideas. Malden, Oxford, Victoria, Berlín: Blackwell Publishing, pp. 852-861.

Kubler, G. (1969). Comment. Comparative Studies in Society and History. An International Quarterly, 11, 4, pp. 398-402. https://doi.org/10.1017/ s0010417500005454

Kuhn, T. (1959/1977). The Essential Tension: Tradition and innovation in Scientific Research. En Kuhn, T. The Essential Tension. Selected Studies in Scientific Tradition and Change. Chicago, London:
The University of Chicago Press, pp. 225-239.

Kuhn, T. (1969). Comment. Comparative Studies in Society and History. An International Quarterly, 11, 4, pp. 403-412. https://doi.org/10.1017/ S0010417500005466

Kuhn, T. (1970/1977). Logic of Discovery or Psychology of Perception. En Kuhn, T. The Essential Tension. Selected Studies in Scientific Tradition and Change. Chicago, London: The University of Chicago Press, pp. 266-292.

Kuhn, T. (1987/1996). ¿Qué son las revoluciones científicas? En Kuhn, T. ¿Qué son las revoluciones científicas? y otros ensayos. Barcelona, Buenos Aires, México: Paidós.

Kuhn, T. (1995). La estructura de las revoluciones científicas. México: Fondo de Cultura Económica.

Lailach, M. (2007). Land Art. Köln: Taschen.

Lorenzano, C. (1982). La estructura psicosocial del arte. México: Siglo XXI

Malevich, K. (1915). From Cubism and Futurism to Suprematism: The New Painterly Realism. En Bowlt, J. (ed.). (1991). Russian Art of the Avant Garde. Theory and Criticism. Thames and Hudson.

Mander, K. (2012). Vidas de los pintores flamencos, holandeses y alemanes. Madrid: Casimiro Libros.

Metzinger, J. y Gleizes, A. (1912/1995). De “Cubismo". En Chipp, H. Teorías del arte contemporáneo. Madrid: Akal. pp. 226-236.

Micheli, M. (1984). Las vanguardias artísticas del siglo XX. Madrid: Alianza.

Mitchel, W. J. T. (ed.). (2002). Landscape and Power. Chicago, London: University of Chicago Press.

Mondrian, P. (2005). Realidad natural y realidad abstracta. México: Ediciones Coyoacán.

Panofsky, E. (1936/2000). El estilo y el medio en la imagen cinematográfica.

Paul, C. (2008). Digital Art. London: Thames and Hudson.
Pittman, L., Gerstler, A. y Eliel, C. (2006). Lee Mullican. An Abundant Harvest of Sun. Los Angeles: Los Angeles County Museum of Art.

Quaranta, D. (2013). Beyond New Media Art. Brescia: Link Editions.

Roever, M. (ed.). (c. 1994). Amsterdam Years, 1892-1912. Amsterdam: Gemeentearchief.

Salmon, A. (1912/1995). Historia anecdótica del cubismo. En Chipp, H. Teorías del arte contemporáneo. Fuentes artísticas y opiniones críticas. Madrid: Akal, pp. 218-226.

Schama, S. (1996). Landscape of Memory. New York: Vintage Books.

Schama, S. (2002). La auténtica cuadrícula: para entender a Mondrian. En Schama, S. Confesiones y encargos. Barcelona: Península Atalaya.

Shapiro, M. (1962/1994). Style. En Schapiro, M. Theory and Philosophy of Art: Style, Artist, and Society. Selected Papers. Nueva York: George Braziller, pp. 51-102.

Smithson, R. y Roth, M. (1973/2004). An Interview with Robert Smithson. En Tsai, E. y Butler C. Robert Smithson. Berkeley, Los Angeles, London: University of California Press.

Stiles, K. y Selz, P. (1996). Theories and Documents of Contemporary Art. A Sourcebook of Artists' Writings. Berkeley, Los Angeles, London: University of California Press.

Tomkins, C. (1999). Duchamp. Barcelona: Anagrama.

Welsh, R. (1998). Piet Mondrian: A catalogue raisonné (vol. 1). Munchen, Nueva York: Prestel.

Whiston Spirn, A. (1998). The Language of Landscape. New Heaven, London: Yale University Press.

Wölfflin, H. (1924/1985). Conceptos fundamentales de la historia del arte. Madrid: Espasa Calpe.

Zervos, C (1932-1978). Pablo Picasso. Catalogue of works (vol. 2). Paris: Cahiers d'Art. 